\title{
Materials for the Human Habitat
}

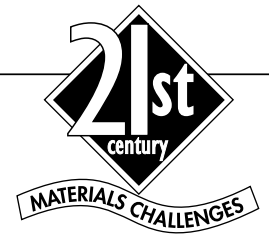

\section{T.N. Gupta}

Form ever follows function —Louis Henri Sullivan

One outstandingly important fact regarding Spaceship Earth, and that is that no instruction book came with it.

-Buckminster Fuller Operating Manual for Spaceship Earth (1969)

\section{Introduction}

People have inhabited all regions of the Earth, from the most benign terrain to the harshest climatic conditions. They have made great efforts to remain and master the natural local environment rather than to migrate to more congenial and comfortable climes. The choice of materials for shelter was thus determined by what was locally available, appropriate, and affordable: ice in polar regions; stone and timber in temperate zones; mud, brick, and thatch in warmer areas; soil and stone in arid deserts; and bamboo and timber in tropical regions. The choice and further improvement of these materials run parallel to the development of human ingenuity. Materials available today reflect such historical interaction, initially through experience, and later based on scientific experimentation, evaluation, and technology development. Today's habitats are monuments that go far beyond societal needs for living, working, public and private congregations or assemblies, leisure activities, commuting, and communication; they are outlets for artistic expression, culture and tradition, prosperity, and for defying the bounds of our previous existence.

Materials for habitats have taken two different routes, solely determined by the economy. Poorer areas remain confined to economic compulsions that at best permit use of materials needed for minimum functional requirements. Space is often cramped, not totally protected against the environment and natural calamities such as earthquakes and hurricanes, and often not connected to adequate sanitation facilities or utilities. The prosperous sector, meanwhile, has ridden high on the wave of materials development, using steel, cement, plastics, and glass, as they have been developed, to build structures of comfort, safety, and beauty. The challenge of the coming decades is one of destroying this habitation divide, not only by making the appropriate construction materials available and affordable to all parts of the world, but also by developing ingenious structures using cheap but locally available materials that provide comfort and safety not accessible or affordable before. Another challenge is to stretch the performance of materials beyond what even the most industrialized countries have done: reaching new heights, inhabiting inhospitable locales such as outer space, and adding smart structures to make our surroundings adapt to our needs.

\section{Energy Needs and Environmental Concems in Developing Countries}

The principal factors affecting a country's materials use are the consumption of energy, natural-resource endowments, and the economy. These three factors, coupled with national policies and programs for the development of habitat, govern the demand for materials, the potential for investment in research and development, domestic industrial production, and importation of goods.

The materials for habitat are traditionally classified under the following categories:

- cement and masonry materials;

- metallic materials;

- wood, natural fibers, polymers, and elastomers;

- glass and ceramic materials;

- insulating, sealing, bonding, electrical, and electronic materials; and

- finishing and decorative materials.

A comparison of energy requirements of building materials are given in Table I. As most of the developing countries have endemic energy scarcity, materials for habitat in these countries tend to be chosen from those demanding low or medium energy for their production. In addition to producing more of the standard building materials such as cement and steel, the developing economies will in the future also focus on the development of materials based on three considerations: (1) the development of new materials and processes with lower energy demands, (2) the design and develop-

Materials Challenges For The Next Century presents a series of articles framing the role of materials in society in the coming century and beyond. ment of new structures resistant to natural disasters, and (3) the development of alternate materials to protect and preserve that which is naturally grown but endangered.

In the coming decades, all developing economies will address the problems of building houses for their populations. In India alone, the housing shortages in rural and urban areas add up to more than 60 million units. This list does not include the renovation of existing structures to make them robust. The demands for more housing have provided large incentives for adding capacities for manufacturing building materials. Figure 1 shows the production of cement in various countries. China and India have multiplied their production capacity many times over, while the growth in developed countries has remained more modest. The Korean growth reflects the export opportunities of this material.

Table I: Comparative Energy Requirements of Building Materials.

\begin{tabular}{|c|c|}
\hline Material & $\begin{array}{l}\text { Primary } \\
\text { energy requirement } \\
(\mathrm{MJ} / \mathrm{kg})\end{array}$ \\
\hline \multicolumn{2}{|l|}{ Very high energy: } \\
\hline Aluminum & $200-250$ \\
\hline Plastics & $50-100$ \\
\hline Copper & $100+$ \\
\hline Stainless steel & 100 \\
\hline \multicolumn{2}{|l|}{ High energy: } \\
\hline Steel & $20-60$ \\
\hline Lead, Zinc & $25+$ \\
\hline Glass & $12-25$ \\
\hline Cement & $5-8$ \\
\hline Plaster board & $8-10$ \\
\hline \multicolumn{2}{|l|}{ Medium energy: } \\
\hline Lime & $3-5$ \\
\hline Clay bricks and tiles & $2-7$ \\
\hline \multicolumn{2}{|l|}{ Concrete } \\
\hline In situ & $0.8-1.5$ \\
\hline Blocks & $0.8-3.5$ \\
\hline Precast & $1.5-8$ \\
\hline Sand-lime brick & $0.8-1.2$ \\
\hline Timber (sawn) & $0.1-5$ \\
\hline \multicolumn{2}{|l|}{ Low energy: } \\
\hline Sand, aggregate & $<0.5$ \\
\hline Fly ash, volcanic ash & $<0.5$ \\
\hline Soil & $<0.5$ \\
\hline Adobe & $<0.2$ \\
\hline
\end{tabular}

Source: Building Materials in India: 50 YearsA Commemorative Volume, edited by T.N. Gupta (Building Materials \& Technology Promotion Council, New Delhi, India, 1998). 


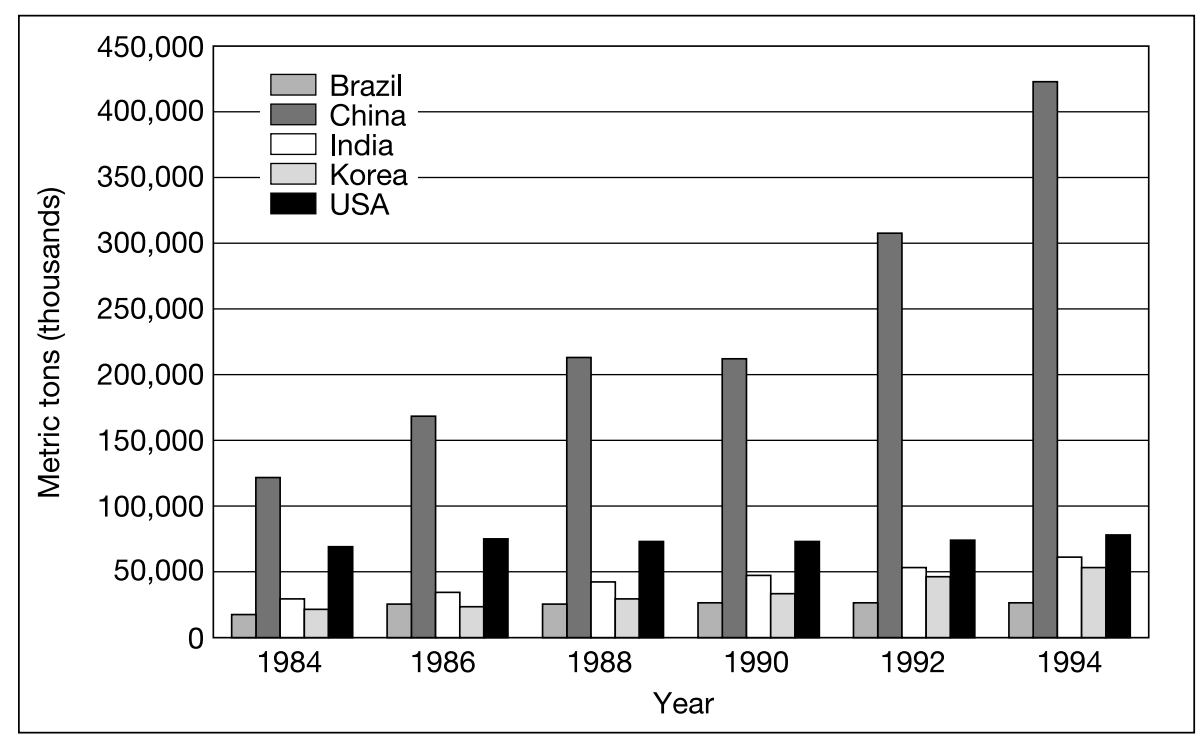

Figure 1. Production of cement.

An approach to saving energy and addressing environmental concerns is to use industrial wastes in the manufacture of building materials. Table II shows some examples of the energy savings achieved through such use of industrial wastes in the manufacture of conventional building materials. In some instances, use of industrial wastes can actually improve the properties of the building material as well. For instance, addition of fly ash in concrete mixes creates discontinuous pore structures and clogs the pore channels with additional calcium silicate formed by the chemical reaction with fly ash. High-durability concrete structures are made with such impermeable concrete, which resists chemical attack and water penetration. W.E. Ellis, Jr. said that "no concrete should be made without fly ash unless there are special reasons" (Concrete Intl. 14 [1992]).

Other options for building materials will include innovations such as compressed earth blocks that are more energyefficient to produce and have the required strength and durability characteristics. Even though these have been known for a few decades, only now have the technologies become mature, wellenough understood, and diffused among developing countries. These are now becoming popular in Africa, South America, and Asia. It is ironic that after so many centuries, developing countries are rediscovering the advantages of the mud block-though suitably mixed and appropriately compressed-over fired bricks or concrete blocks!

Other new materials may come from composites using naturally available fibers and plastics. Jute and coconut-shell fibers (coir), bonded with appropriate resins, are already being used in a few non-load-bearing applications. Conventional plastics are making inroads in many areas, and their use has increased significantly.

Recent earthquake disasters in India and Turkey and storm-ravaged villages and towns in Bangladesh and India have brought into focus the importance of building structures to withstand such natural calamities. In the coming decades, renewed emphasis will be placed on building well-engineered structures that strictly follow building codes and are better designed to resist strong earthquakes and peak wind pressures. Floors and roofs will need to be strengthened, with adequate bearing capacity on stiffer elements, and foundations will incorporate proper anchorages. New lightweight and low-cost composite materials will be needed with high tensile and shear

Table II: Energy Savings in the Manufacture of Building Materials through Use of Industrial Wastes.

\begin{tabular}{|c|c|c|c|}
\hline Building material & Composition & Material compared & $\begin{array}{c}\text { nergy savings } \\
\text { (\%) }\end{array}$ \\
\hline Portland pozzolana cement & $75 \%$ Ordinary Portland cement & $100 \%$ Ordinary Portland cement & 20 \\
\hline Masonry cement & $\begin{array}{l}50 \% \text { Ordinary Portland cement } \\
50 \% \text { Tailings/waste chalk }\end{array}$ & $\begin{array}{l}100 \% \text { Masonry cement } \\
\text { (50\% Ordinary Portland cement }+50 \% \text { limestone) }\end{array}$ & 20 \\
\hline Lime-pozzolana mixture & $\begin{array}{l}25 \% \text { Acetylene gas lime } \\
75 \% \text { Fly ash }\end{array}$ & $\begin{array}{l}25 \% \text { Lime } \\
75 \% \text { Calcined brick }\end{array}$ & 75 \\
\hline $\begin{array}{l}\text { Calcium silicate brick } \\
10 \% \text { lime (waste source) }\end{array}$ & $90 \%$ Fly ash tailings & Burnt clay brick & 40 \\
\hline
\end{tabular}

Source: Building Materials in India: 50 Years-A Commemorative Volume, edited by T.N. Gupta (Building Materials \& Technology Promotion Council, New Delhi, India, 1998). 
strengths and improved compressiveload capacities. The developing countries in the coming decades will be increasingly required to focus on these issues through innovative and cost-effective technology options.

The continuing practice of manufacturing building materials through indiscriminate and thoughtless felling of trees and exploitation of minerals is severely damaging the environment and destroying the forest cover. If the present rate of such practices continue, the tropical forest cover will be depleted. Many developing economies, most notably India, are therefore developing alternative materials, based on agricultural wastes and residues, natural fibers, and plantation timber, that have an added advantage of requiring less

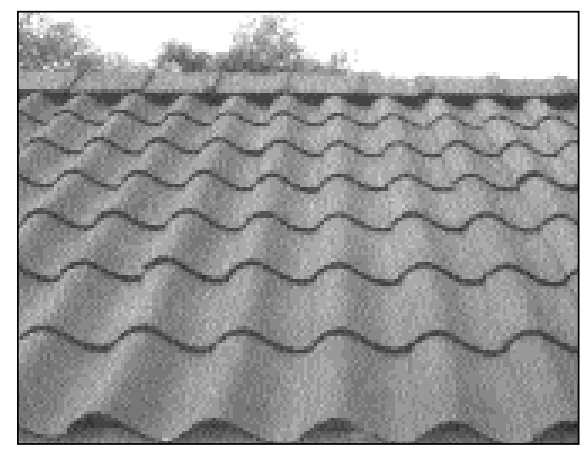

Figure 2. Composite materials, using natural fibers and agroindustrial wastes and byproducts in polymer-cement matrices, are being developed and produced in India. energy to manufacture (see Figure 2). Some of these products are now commercially available for roofing, flooring, and ceiling applications. The challenge in the coming decades will be to further improve the mechanical and environmental properties of these materials and also to develop appropriate standards for their manufacture and application.

\section{Reach for the Sky, or the House that Bill Built}

Skyscrapers have always captured our imagination, and there has been keen competition among builders to make them ever taller. The tallest skyscraper, Petronas Twin Towers in Kuala Lumpur, Malaysia is unique in many respects, including the fact that concrete has been chosen instead of steel as the material for the columns (see Figure 3). New developments in the compositions of concrete, including the fly ash mentioned earlier and also microsilica and other inorganic compounds, have increased strength and reduced environmental degradation due to water seepage. The increased strength of concrete combined with its ease of construction has brought this material forward as a competitor to steel; steel has not lost the battle, though, with its improved mechanical properties and environmental compatibility. The coming years will see more and taller skyscrapers using both of these materials. Frank Lloyd Wright's dream of building a mile-high skyscraper in Chicago may still become realizable when lightweight but structurally strong composite materials start to be

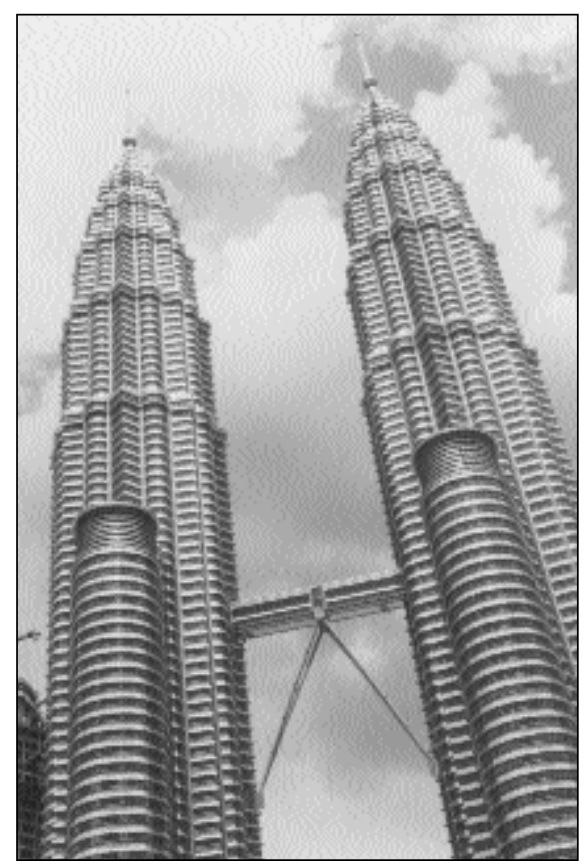

Figure 3. Petronas Twin Towers in Kuala Lumpur, Malaysia, the tallest-structure worldwide, uses concrete instead of steel as the material for the column. Courtesy of the Embassy of Malaysia.

used as building materials for higher floors, while at the same time providing adequate shear strength at those levels that use concrete columns. Composites provide the kind of options that enable builders to overcome some of the practical constraints in building tall structures.

\section{Smart Materials and Structures}

A few building applications of sensors will be extremely attractive in the coming decades. The first concerns their applications to the integrity of the building structure itself. For instance, properly integrated sensors could measure the corrosion of reinforcing steel bars in concrete through changes in the $\mathrm{pH}$ level and inject appropriate remedial chemicals to that location. Sensors may also be used to measure wind speeds or earthquake-generated pressures and provide for a temporary increase in strength at anchorage points of the roof and other vulnerable locations. Sensors and semiconductor photovoltaics can become integral parts of the structure, providing for the generation of electrical energy. While newer semiconductors are being pursued to improve the effi-

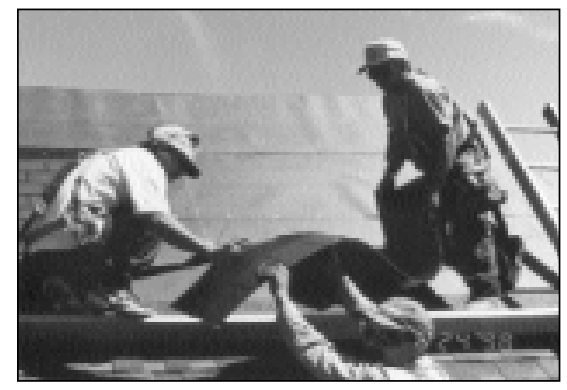

UNI-SOLAR solar shingle installation. Courtesy of United Solar Systems Corp.

ciency of energy-generation (the efficiency of silicon photovoltaics is between $10 \%$ and $20 \%$ ), a more optimal route would be to integrate the photovoltaic modules as parts of the structure itself. Solar shingles illustrate this trend (see Figure).

For example, Ovonic amorphous, flexible, thin-film triple junction photovoltaics made on a continuous web, machine by United Solar Systems, produce a half-mile-long solar cell, which is then utilized as shingles. The solar cell is installed in the same way as conventional shingles and as standing seam metal roofs; neither need superstructures as do conventional crystalline photovoltaics. Energy storage can be provided by nickel-metal hydride batteries installed anywhere in the building. These photovoltaics can be low-cost, prosaic, and ubiquitous, covering buildings rather than land, and helping to solve the problems of pollution, climate change, and dependence on fossil fuels. 


\section{Inflatable Housing May be Launched in Space}

The International Space Station is still not up and orbiting, but many of its parts are under fabrication, including the capsule where crew members will live and work. TransHab, an inflatable module proposed as crew living quarters, is an example of the potential role of materials in support of future living environments. Conceptualized by the National Aeronautics and Space Administration's (NASA) Lyndon B. Johnson Space Center in Houston, Texas, this proposed space-station component would be the last scheduled element completing the station in late 2004.

The almost two-dozen layers of TransHab's foot-thick shell are fashioned to break up particles of space debris and tiny meteorites. The outer layers protect multiple inner bladders that hold in the module's air. The shell also provides insulation from temperatures in space that can range from $-200^{\circ} \mathrm{F}$ to $+250^{\circ} \mathrm{F}$. The outer insulation consists of blankets and mylar that are on the outside of all space-station modules. Protection from debris is provided by layers of Nextel cloth spaced by foam rubber and bulletproof Kevlar fabric. The restraint layer consists of woven Kevlar, which holds TransHab's shape. Pressure bladders are made up of air-tight combitherm materials alternated with layers of Kevlar. The inside wall is made up of Nomex cloth for scuff protection.

The overall concept is a hybrid structure that combines the packaging and mass efficiencies of an inflatable structure with the advantages of a load-bearing hard structure. Made from lightweight, carbon-fiber composite materials, the central core is a hard tunnel with a shell interface that provides three floors and dividers between various compartments. A center passageway runs the length of the module, providing access to all levels. The flooring and dividers are unfolded and extended after the module is inflated. An integral water-storage tank wraps around the middle level's crew quarters to provide protection from solar-radiation storms when needed. Some areas of the floor are open as passageways between levels, creating a roomy atrium effect. A bottom tunnel houses compressed-air tanks used for the initial inflation of TransHab as well as other exterior equipment.

The technology of inflatable structures may find uses in future space exploration beyond Earth orbit, such as for interplanetary spacecraft or as the ultimate "mobile home" on the Moon or Mars. In addition to benefits for the space station, a concept like TransHab may provide a valuable test of technologies that pave the way to the future in

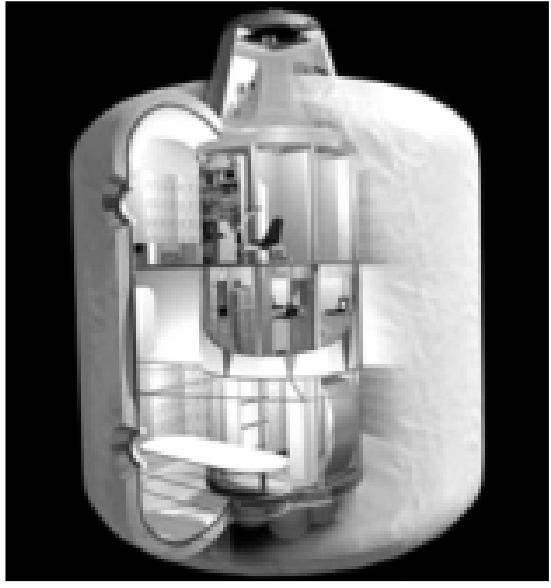

TransHab, an inflatable module to house crew members in the International Space Station.

space. The development of innovative inflatable technologies for space may also find uses on Earth.

TransHab module animations and pictures and a detailed view of the module's four levels and inflatable shell can be accessed on Web site http://spaceflight. nasa.gov/station/assembly/elements / transhab/.
Skyscrapers may not always remain as an exclusive symbol of prosperity. The need for such large buildings with their congregations of workers may indeed become irrelevant if information technology continues to progress the way it has for the past several decades. The house that Bill Gates of Microsoft built shows the trend. The ubiquitous presence of computers and sensors linking occupants and visitors with machines provides a level of information exchange (command and compliance) that helps to modify the microenvironment to suit individual needs. It is possible that such sensors, more than mere materials, are going to provide the real breakthroughs in innovating the habitat in the coming decades.

In the words of Peter Drucker, "Longrange planning does not have to deal with future decisions, but with the future of present decisions." The emerging areas, while capturing the highest pitch of human creativity, will be based on integration of traditional wisdom, scientific and technological developments, and innovations in the coming century.

\section{Acknowledgments}

The author gratefully acknowledges discussions with Dr. P. Rama Rao, Vice Chancellor, Osmania University, Hyderabad, India; and contributions from Stanford R. Ovshinsky of United Solar Systems Corp. for information on solar shingles; and the Embassy of Malaysia for the photo of Petronas Twin Towers.

FOR FURTHER READING: F. Moavenzadeh, Concise Encyclopaedia of Building $\mathcal{E}$

Construction Materials (Pergamon Press, Elmsford, New York, 1990); T.N. Gupta,
Theme of Regional Consultation: Charting New Directions for Housing Policies in Africa, Regional Consultation on the Construction Industry with Special Focus on Housing for LDCs in Africa, 1993; New and Advanced Materials_Emerging Technology Series 3 (United Nations Industrial Development Organization, Vienna, 1996); C. Pelli, Cosmic Pillars: Philosophy of Tall Buildings, in Collected Papers of Habitat and the High Rise, Council on Tall Buildings and Urban Habitat.

T.N. Gupta is the Executive Director of the Building Materials and Technology Promotion Council, an interdisciplinary organization set up by the government of India. Before serving the organization, Gupta was a scientist at the Central Building Research Institute at Roonkee, India, for over two decades.

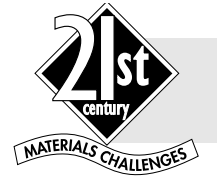

Access MRS Web site www.mrs.org/publications/bulletin/21stcen/ for articles on Materials Challenges for the Next Century 